\title{
Strain engineering for improved expression of recombinant proteins in bacteria
}

Tomohiro Makino ${ }^{1,2,6+}$, Georgios Skretas ${ }^{5 \dagger}$ and George Georgiou ${ }^{1,2,3,4^{*}}$

\begin{abstract}
Protein expression in Escherichia coli represents the most facile approach for the preparation of non-glycosylated proteins for analytical and preparative purposes. So far, the optimization of recombinant expression has largely remained a matter of trial and error and has relied upon varying parameters, such as expression vector, media composition, growth temperature and chaperone co-expression. Recently several new approaches for the genomescale engineering of $E$. coli to enhance recombinant protein expression have been developed. These methodologies now enable the generation of optimized $E$. coli expression strains in a manner analogous to metabolic engineering for the synthesis of low-molecular-weight compounds. In this review, we provide an overview of strain engineering approaches useful for enhancing the expression of hard-to-produce proteins, including heterologous membrane proteins.
\end{abstract}

\section{Introduction}

Since the beginning of the modern biotechnology era in the late 70s, Escherichia coli has been used extensively for protein overexpression due to its rapid growth rate, ease of high-cell-density fermentation, low cost and, most importantly, the availability of excellent genetic tools. The optimization of recombinant protein expression in E. coli has been carried out largely by trial and error by varying simple parameters such as expression vectors, host strains, media composition, and growth temperature.

During the past years, extensive studies have shown that the replacement of codons within a heterologous gene with synonymous ones used preferentially in the expression host (codon optimization), and the manipulation of the nucleotide sequence of the translational initiation region can have a profound effect on recombinant protein yields [1-4]. mRNA secondary structures, RNase cleavage sites and ribosome-binding site sequestering sequences have been introduced into expression constructs in efforts to increase mRNA stability, improve transcription termination and translation efficiency [5]. Currently, a wide selection of commercially available

\footnotetext{
* Correspondence: gg@che.utexas.edu

+ Contributed equally

'Department of Chemical Engineering, The University of Texas at Austin, Austin, Texas 78712, USA

Full list of author information is available at the end of the article
}

expression vectors is provided with different origins of replication, different promoters, translation initiation regions, antibiotic resistance markers, transcription terminators, etc. The selection of the proper vector together with the use of codon-optimized genes [6,7] is in many instances sufficient to enable the accumulation of the target protein at an appreciable level. This optimization strategy, however, does not address problems related to protein misfolding and solubility. Trial and error optimization of growth temperature, media optimization of induction conditions, the use of fusions to solubilizing partners and chaperone co-expression have to be deployed to achieve better yields of biologically active product. For example, fusions of the protein of interest with partners, such as the maltose-binding protein (MBP) or glutathione-S-transferase (GST) [8-10], as well as coexpression of proteins that can assist in folding, notably molecular chaperones/co-chaperones (GroEL/GroES, DnaK/DnaJ etc) [11], are used routinely to increase soluble protein yields. Nevertheless, there are many proteins for which none of these approaches are effective.

Directed evolution of the polypeptide sequence for improved synthesis and folding in a prokaryotic host, also termed as "expression maturation", has been employed successfully for a variety of complex heterologous proteins including mammalian $\mathrm{G}$ protein-coupled receptors (GPCR), hemoglobin, antibody fragments and other proteins [12-15]. In expression maturation, the gene 
encoding the target protein is subjected to random mutagenesis (e.g. by error-prone PCR), the library of mutant genes is expressed, and variants with increased solubility are identified, either by applying selective pressure or by high-throughput screening [12-15]. The limitations of this approach are first, that it lacks generality since it needs to be applied for every individual protein target; second, the need for a high-throughput screen for expression applicable to the protein of interest; and third, the concern that the selected mutations may also affect the function, stability, or the structure of the protein.

One alternative to expression maturation is to engineer host strains that are suitable for the expression of particular classes of proteins, such as proteins with complex disulfide topologies, membrane proteins, or proteins with intrinsically slow folding kinetics, which, in general, are more prone to misfolding and aggregation. The advantage of this approach is its broader generality since it leads to the generation of high-expression strains for a variety of polypeptides that share some common features. Furthermore, analysis of the chromosomal or vector mutations that confer enhanced expression can provide a better understanding of the rate limiting steps in protein expression and perhaps be of general utility for the production of other similar proteins.

Here, we will provide a review of current efforts to enhance recombinant protein production in $E$. coli through genetic and genome-scale engineering. Relevant technologies for the creation and isolation of overexpressing mutants and successful examples of increased protein yields are presented. The terms "genetic engineering" and "strain engineering" are used interchangeably throughout this text.

\section{Strain/genetic engineering for enhanced protein expression in bacteria}

Chromosomal lesions such as nucleotide substitutions, gene deletions or insertions and, alternatively, overexpression of homologous or heterologous genes can all influence the expression of target proteins. Genetic modifications can be introduced into DNA in a targeted manner within a specific cellular pathway known to be involved in protein biogenesis. Alternatively, when the causes of poor expression are not known, a library of random chromosomal gene fragments can be cloned and co-expressed with the target protein or, the entire genome may be subjected to random mutagenesis, followed by screening to isolate clones that confer increased protein production.

\section{Targeted strain engineering strategies}

Targeted strain engineering focuses on the introduction of mutations in DNA sequences known to affect protein synthesis, degradation, secretion or folding. Several excellent reviews describing the strategies for improving protein secretion or for limiting protein degradation have already been published [16-19]. Therefore, we will focus here only on the engineering of bacterial strains for improved protein synthesis and/or folding.

\subsection{Engineering of mRNA stability and translational efficiency}

In bacteria, the half-life of mRNA is much shorter than in eukaryotic cells and can be the rate limiting step in translation and, hence, in protein synthesis. The endonuclease RNaseE catalyzes the first, rate-determining step in the cleavage of numerous transcripts in E. coli. Mutations, such as the well characterized rne131 allele, that attenuate the activity of this essential protein, confer increased mRNA stability, which can in turn result in higher protein expression levels [20]. A BL21 derivative strain carrying the rne131 allele is commercially available by Invitrogen under the brand name BL21 Star ${ }^{\mathrm{TM}}$.

As mentioned briefly above, translational efficiency can be dramatically affected by codon usage and by the sequence of the translation initiation region. Numerous reports have demonstrated that the use of engineered strains that co-express tRNAs for rare codons such as the Rosetta ${ }^{\mathrm{TM}}$ strains from Invitrogen and the BL21 CodonPlus strains from Novagen can enhance recombinant protein production significantly [21,22].

\subsection{Improving protein folding by chaperone co-expression}

A common, and occasionally successful, strategy for preventing protein aggregation is the co-expression of molecular chaperones. The biochemistry and mechanism of action of bacterial molecular chaperones and enzymes that assist folding have been reviewed previously [23], and will not be covered in detail here. It is important to note that folding factors such as DnaK/ DnaJ/GrpE, GroEL/GroES, IbpA/IbpB, Skp, trigger factor and FkpA have been used successfully to prevent protein aggregation of cytoplasmic or periplasmic proteins [24-28]. The latter two proteins also display X-Pro isomerization activity but their function in assisting protein folding has been attributed primarily to their role as chaperones [29,30]. DnaK/DnaJ/GrpE, GroEL/GroES and $\mathrm{ClpB}$ can function synergistically in assisting protein folding and therefore expression of these chaperones in combinations has been shown to be beneficial for protein expression [11,31].

\subsection{Expression of disulfide-bonded proteins}

Many biotechnologically important proteins contain disulfide bonds. The cytoplasm of E. coli is normally maintained in a reduced state that precludes the formation of disulfide bonds via the action of the thioredoxin and glutaredoxin/glutathione enzyme systems [32]. Therefore, proteins with disulfides normally need to be exported into the periplasm. In the periplasm, disulfide bond formation and isomerization is catalyzed by the 
Dsb system, which comprises DsbABCD and G. Coexpression of the cysteine oxidase DsbA, the disulfide isomerase DsbC or combinations of the Dsb proteins, have been employed for the successful expression of numerous heterologous proteins such as scFvs, plasminogen activators, human nerve growth factors and others [25,33-35].

Mutant strains defective in glutathione reductase (gor) or glutathione synthetase $(g s h A)$ together with thioredoxin reductase $(\operatorname{tr} x B)$ render the cytoplasm oxidizing. These strains are unable to reduce ribonucleotides and therefore cannot grow in the absence of exogenous reductant, such as dithiothreitol (DTT). Suppressor mutations in the gene $a h p C$, which encodes the peroxiredoxin AhpC, allow the channeling of electrons onto the enzyme ribonulceotide reductase enabling the cells to grow in the absence of DTT. In such strains, exposed protein cysteines become readily oxidized in a process that is catalyzed by thioredoxins, in a reversal of their physiological function, resulting in the formation of disulfide bonds. A number of heterologous multi-disulfidebonded proteins have been produced in the cytoplasm of E. coli FA113 cells (trxB gor $a h p C^{*}$ ) or OrigamiтM (Novagen) at high yields [36]. Additionally, it was recently shown that bacterial strains with different mutations in the thioredoxin/thioredoxin reductase and glutaredoxin/glutathione reductase genes and containing different suppressor mutations in alleles of $a h p C$, display dramatic differences in the kinetics of cysteine oxidation in the cytoplasm and in the yield of correctly folded proteins [28,37].

Very recently, Ruddock and colleagues have shown that overexpression of the sulfhydryl oxidase Erv1p from the inner membrane space of yeast mitochondria enables high-level production of a variety of complex, disulfide-bonded proteins of eukaryotic origin in the cytoplasm of E. coli [38]. Remarkably, these investigators found that disulfide bond formation upon Erv1p coexpression could take place even in the absence of $\operatorname{tr} x B$ gor mutations [39].

\subsection{Glycoprotein production in E. coli}

Until recently, protein glycosylation was considered a post-translational modification which can only be carried out in eukaryotes. In 2002, it was discovered that the enteropathogenic bacterium Campylobacter jejuni can perform protein $N$-glycosylation. Subsequent transfer of the $\mathrm{pgl}$ locus led to the development of $E$. coli strains which could perform $N$-glycosylation of the C. jejuni proteins AcrA and PEB3 [40]. The pgl locus consists of five putative glycosyltransferases ( $p g l A C H I J)$, an oligosaccharyl transferase $(p g l B)$, four enzymes involved in sugar biosynthesis ( $g a l E, p g l D E F)$, and a flippase $(w l a B)[41,42]$. pglB mutants having relaxed specificity have been engineered [41], thus opening the way for the incorporation of diverse glycan structures onto a target polypeptide. Furthermore, forward engineering using shotgun proteomics and metabolic flux analysis has been applied to significantly improve the efficiency of protein glycosylation in E. coli [43]. Several groups have started to utilize the $C$. jejuni pgl $N$-linked glycosylation platform for biotechnological applications, including the generation of glyco-conjugated vaccines in bacteria $[44,45]$. Very recently, two groups have reported the display of glycoproteins onto filamentous phage, which in turn may enable the isolation of novel types of glycoproteins from combinatorial libraries [46,47].

\subsection{Acetylated protein production in E. coli}

Acetylation is a very commonly encountered protein modification, which is important for regulation in key cellular processes $[48,49]$. In eukaryotes, most proteins are acetylated at the alpha-amino group of the N-terminal amino acid or at the epsilon-amino group of internal lysines. In general, eukaryotic N-terminal acetylation is carried out by specific $N$ - $\alpha$-acetyltransferase (Nat) complexes and is thought to take place co-translationally at the ribosome [50]. This protein modification, however, is rarely encountered in bacteria, and in contrast to eukaryotes, it takes place in a post-translational manner [51]. In a very recent study, overexpression of the bacterial $N$ - $\alpha$-acetyltransferase RimJ was found to be sufficient for the production of fully acetylated recombinant thymosin alpha 1 in E. coli [52]. Even more recently, Mulvihill and coworkers demonstrated that co-expression of one of the members of the Nat complex of the fission yeast (NatB) with its target substrate proteins could successfully produce a number of acetylated proteins of human and yeast origin in $E$. coli [53]. These findings demonstrate that a wide variety of acetylated proteins could be potentially produced recombinantly in E. coli.

\section{Global genetic/strain engineering}

Strains that confer improved protein expression can be engineered by screening libraries of chromosomal mutants or plasmid-encoded expression libraries of heterologous or native genes. An important advantage of this approach is that no a priori hypotheses or extensive knowledge regarding bottlenecks in recombinant protein expression is required. Identification and analysis of the effects of the genetic lesions isolated in this process can in turn provide a better understanding of the pathways that limit the expression of the desired protein. The key factors for successful strain engineering by library screening approaches are: 1) the type of genetic modification applied 2) the quality of the constructed library, and 3) the availability of a high-throughput screen that can correctly identify clones displaying the desired phenotype. 
Libraries of bacteria containing lesions randomly distributed over the entire chromosome can be readily generated by classical mutagenesis methods, such as UV irradiation, chemical mutagens, and random transposon mutagenesis. A very useful tool for studying the effect of gene knockouts on recombinant protein expression and other properties/phenotypes is the Keio collection, a publicly available library of all single knockouts of all the non-essential E. coli $\mathrm{K}-12$ genes [54].

In addition to the classical mutagenesis strategies, new techniques for genome engineering have been developed recently for generating libraries in which the expression of chromosomally encoded genes can been up- or downregulated. These techniques include global transcription machinery engineering (gTME) [55] and trackable multiplex recombineering (TRMR) [56]. These and other genome engineering technologies may be employed to access phenotypes that may be difficult to obtain via classical mutagenesis approaches [57].

\subsection{Strain engineering by classical mutagenesis}

One of the most frequently encountered phenotypic consequences of recombinant protein expression is growth retardation or complete growth arrest of the host following induction of gene overexpression. More than a decade ago, Walker and coworkers isolated E. coli BL21(DE3) mutant strains carrying spontaneously acquired suppressor mutations that alleviate the toxicity caused by the production of cytotoxic proteins under the control of the strong T7 promoter [58]. These strains, which are called C41 and C43 or "Walker strains", are widely used to produce increased levels of hard-to-express proteins primarily because they allow increased biomass production. Not surprisingly, it was later found that the mutations in these strains reduce the translational efficiency of the T7 RNA polymerase [59]. C41 and C43 are currently commercially available by Avidis.

Recently, Bowie and co-workers used a combination of the mutagenic base analog 2-aminopurine and the mutator gene mutD5 (a mutated dnaQ gene causing a DNA proofreading defect), to evolve E. coli strains which accumulate markedly enhanced amounts of a variety of different Mycobacterium tuberculosis rhomboid family proteins and other prokaryotic and eukaryotic integral membrane proteins [60]. These strains were found to produce up to 90 -fold higher amounts of protein compared to the parental strain TOP10. In an analogous manner, our group has used the chemical mutagen $N$-methyl- $N$ '-nitro- $N$-nitrosoguanidine to generate $E$. coli mutants that confer up to 5 -fold greater yields of properly assembled full-length IgG antibodies in the bacterial periplasm [61]. In another example of classical strain mutagenesis for enhanced recombinant protein production, Skretas and Georgiou used insertional mutagenesis of the Tn5 transposon together with fluorescence-activated cell sorting (FACS), to isolate E. coli MC4100A variants that accumulate increased amounts of the membrane-inserted human GPCR central cannabinoid receptor (CB1) [62].

Genes, gene fragments or operon fragments that favorably affect protein expression can be isolated from plasmid libraries co-expressing genomic fragments. Alternatively, individual intact genes can be identified using the ASKA library, an ordered library of all the E. coli ORFs transcribed from the inducible T5lac promoter [63]. Using this library, our group identified $E$. coli proteins that enhanced the yields of the membrane-embedded form of the human GPCR bradykinin receptor 2 (BR2) [64]. One of these, the putative DNAbinding protein of unknown function $\mathrm{YbaB}$, conferred a $\sim 10$-fold increase in the accumulation of membraneintegrated and folded BR2, as well as a variety of membrane proteins tested of either prokaryotic or eukaryotic origin.

The described genetic engineering strategies for enhancing recombinant protein production in bacteria are summarized in Table 1.

\subsection{Genome engineering}

Genome engineering techniques refer loosely to a group of methods for introducing desired genetic diversity within known regions of the chromosome. Modifying the transcriptional landscape of $E$. coli, e.g. by generating libraries of randomized transcription factors or by mutating components of the RNA polymerase, is an effective means of generating complex phenotypes. Although genome engineering has not yet been applied extensively to the optimization of recombinant protein expression, it holds great promise for the creation of the next generation of $E$. coli host strains for protein production. The great advantage of these methods is that they can have a global impact on cellular pathways and physiology [65]. Examples of genome engineering methods likely to be of particular interest for expression optimization are outlined below and summarized in Table 2.

Global transcription machinery engineering (gTME) is a new tool that enables the reprogramming of the cellular transcriptome through random mutagenesis (e.g. by error-prone PCR) of selected components of the transcriptional machinery, such as the $E$. coli sigma factor $\sigma^{70}$, the $\alpha$ subunit of the $E$. coli RNA polymerase, or the $S$. cerevisiae TATA-binding transcription factor Spt15p. Screening of plasmid-encoded gTME libraries was used to isolate strains with increased tolerance to alcohols and for enhanced production of small molecules, such as lycopene (50\% increase), L-tyrosine (150\% increase), hyaluronic acid (60\% increase), and others [55,66-68].

Zinc fingers are highly specific DNA-binding protein domains that recognize three-base-pair sequences and 
Table 1 Genetic engineering strategies which have been applied to the enhancement of recombinant protein production in bacteria

\begin{tabular}{|c|c|c|c|}
\hline Method & Strain & Target protein & Reference \\
\hline $\begin{array}{c}\text { Spontaneous chromosomal } \\
\text { mutagenesis }\end{array}$ & $C(1(D E 3), C 43(D E 3)$ & 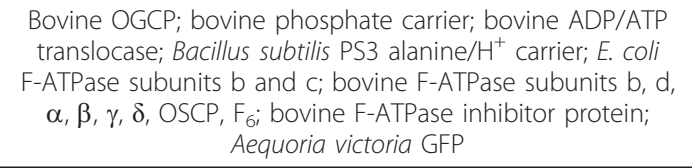 & {$[58]$} \\
\hline \multirow[t]{2}{*}{$\begin{array}{l}\text { Chromosomal mutagenesis } \\
\text { using chemical mutagens or } \\
\text { mutator genes }\end{array}$} & $\begin{array}{c}\text { EXP-Rv1337-1, EXP-Rv1337-2, EXP-Rv1337-3, } \\
\text { EXP-Rv1337-4, EXP-Rv1337-5 }\end{array}$ & $\begin{array}{c}\text { Mycobacterium tuberculosis Rv1337, M. tuberculosis Rv2746, } \\
\text { M. tuberculosis Rv2835, M. tuberculosis Rv0110, } \\
\text { Methanocccus jannaschii rhomboid (MJR), Drosophila } \\
\text { melanogaster rhomboid 1 (Rho1) }\end{array}$ & [60] \\
\hline & GS1, TM1, TM2, TM3, TM4, TM5, TM6 & Variants of human IgG1 & [61] \\
\hline Transposon mutagenesis & 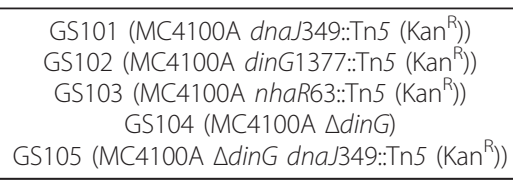 & Human central cannabinoid receptor (CB1) & [62] \\
\hline $\begin{array}{l}\text { Co-expression of the ASKA } \\
\text { library }\end{array}$ & $\begin{array}{l}\text { MC4100A (+ybaB) } \\
\text { MC4100A (+yciQ) } \\
\text { MC4100A (+glpQ)* }\end{array}$ & $\begin{array}{c}\text { Human bradykinin receptor } 2 \text { (BR2), CB1, human neurokinin } \\
\text { (substance P) receptor } 1 \text { (NKR1), E. coli YidC, E. coli CstA, } \\
\text { human stearoyl-CoA desaturase (SCD) }\end{array}$ & [64] \\
\hline
\end{tabular}

${ }^{*} \mathrm{MC}$ 100A (+name of gene) denotes an MC 100 strain overexpressing the E. coli gene specified in parentheses.

are found in a variety of transcriptional regulatory proteins. A single transcription factor can include several of these motifs, which can be assembled in a highly modular fashion to target loner motifs and confer sequence selectivity. Fusions of random combinations of zinc fingers with activator or repressor domains have been employed to introduce high levels of diversification of transcription, which in turn can generate diverse complex phenotypes, such as tolerance to high and low temperatures, drug resistance, osmotic tolerance, and differentiation in different organisms, such as Saccharomyces cerevisiae, mammalian cells, and E. coli [69-71]. Such libraries of random combinations of zinc fingers can potentially be used to generate engineered bacterial strains, whose evolved transcriptome affects favorably recombinant protein production.

Very recently, Gill and co-workers have developed a creative methodology, termed trackable multiplex recombineering (TRMR), for constructing libraries of genetically modified microorganisms based on homologous

Table 2 Representative genome engineering strategies which could be applied to the enhancement of recombinant protein production in bacteria

\begin{tabular}{|c|c|c|c|c|}
\hline Method & Targeted cellular component & Target organism & Engineered phenotype & References \\
\hline \multirow[t]{3}{*}{$\begin{array}{l}\text { Global transcription } \\
\text { machinery } \\
\text { engineering (gTME) }\end{array}$} & $\begin{array}{c}\text { General sigma factor } \sigma^{70} \text {, stationary } \\
\text { phase sigma factor } \sigma^{\mathrm{s}}, \text { RNA } \\
\text { polymerase a subunit }\end{array}$ & E. coli & $\begin{array}{c}\text { Ethanol, butanol, isobutanol, pentanol, and 3- } \\
\text { pentanol tolerance; lycopene, L-tyrosine, and } \\
\text { hyaluronic acid production }\end{array}$ & {$[55,66,68]$} \\
\hline & Transcription factor Spt15p & S. cerevisiae & Ethanol tolerance and production & {$[67]$} \\
\hline & General sigma factor & $\begin{array}{l}\text { Lactobacillus } \\
\text { plantarum }\end{array}$ & lactic acid and hydrochloric acid tolerance & [95] \\
\hline \multirow[t]{3}{*}{$\begin{array}{l}\text { Libraries of artificial } \\
\text { zinc fingers }\end{array}$} & Zinc fingers & S. cerevisiae & $\begin{array}{l}\text { Tolerance to heat and osmotic stress; } \\
\text { ketoconazole resistance }\end{array}$ & [69] \\
\hline & & $\begin{array}{l}\text { Mouse neuroblastoma } \\
\text { cells }\end{array}$ & $\begin{array}{l}\text { Neurogenesis, differentiation of neuroblasts to } \\
\text { osteoblasts, proliferation rate }\end{array}$ & {$[69]$} \\
\hline & & E. coli & Tolerance to heat, cold, and osmotic stress & {$[70,71]$} \\
\hline $\begin{array}{l}\text { Trackable multiplex } \\
\text { recombineering } \\
\text { (TRMR) }\end{array}$ & $>95 \%$ of all individual E. coli genes & E. coli & $\begin{array}{l}\text { Tolerance to salicin, D-fucose, methylglyoxal, } \\
\text { valine, and lignocellulosic hydrolysate }\end{array}$ & {$[56]$} \\
\hline \multirow[t]{3}{*}{ Genome shuffling } & Chromosome & Streptomyces fradiae & Tylosin production & [72] \\
\hline & & $\begin{array}{l}\text { A strain of } \\
\text { Lactobacillus }\end{array}$ & Tolerance to lactic acid & [73] \\
\hline & & $\begin{array}{l}\text { Sphingobium } \\
\text { chlorophenolicum }\end{array}$ & Degradation of pentachlorophenol & [74] \\
\hline
\end{tabular}


recombination of pools of synthetic oligos [56]. Briefly, two sets of oligoDNA cassettes were synthesized: Each contained 5' and 3' recognition sequences for homologous recombination of the ribosome-binding site (RBS) of each one of the 4,077 protein-coding genes of $E$. coli MG1655, interrupted by a gene-specific tracking sequence, an antibiotic resistance marker for selection of successful recombination, and an "up cassette" or a "down cassette". The "up cassette" contained the sequences of the strong inducible promoter $\mathrm{P}_{\text {LtetO-1 }}$ with a RBS, whose function was to generally up-regulate the expression of its target gene, while the "down cassette" contained an inert sequence, whose function was to generally down-regulate gene expression. Homologous recombination of these oligonucleotides enabled the creation of pools of bacteria displaying upregulation or downregulation of genes at a genomic scale. The library of the mutant strains $(2 \times 4,077=8,154$ total $)$ was subsequently subjected to selection for growth under various conditions. Using this approach, Warner et al. reported the isolation of thousands of clones with improved growth phenotype in various conditions within a week [56]. The isolated clones could be easily characterized by sequencing or by microarray analysis using the recombined tag sequences to identify the genes responsible for the evolution of these complex phenotypes. However, it is not clear yet if the TRMR libraries of bacterial cells with upand down-regulated genes will enable the evolution of novel traits which are different than those achieved with the use of the ASKA library and the Keio collection, respectively.

Once a collection of strains displaying increased expression has been created by one of the techniques discussed so far, whole genome recombination or "shuffling" may be employed to create a library of clones containing combinations of alleles that contribute to better expression. Strains containing combination of alleles that act synergistically can then be isolated [72]. Consecutive rounds of genome shuffling have been shown to result in the rapid emergence of complex phenotypes in a variety of microorganisms, such as a nine-fold improvement of tylosin production in Streptomyces fradiae, a three-fold increase in lactic acid production in a poorly characterized industrial strain of Lactobacillus, and a dramatically enhanced ability to degrade the anthropogenic pesticide pentachlorophenol in Sphingobium chlorophenolicum [72-74]. Genome shuffling in E. coli, however, is rather inefficient [75] and, therefore, new techniques will have to be developed before this methodology becomes routine for this organism.

\subsection{Screening/Selection platform}

An important issue in the engineering of novel strains for improved expression is how to monitor the yield of the desired protein in a high-throughput manner. For small libraries, microtiter well plates can be used to screen up to a few thousand clones. Immunoassays, namely enzyme-linked immunosorbent assays (ELISAs) and 96-well Western blot analyses can be used to quantify the level of soluble protein when no functional assay is available. However, screening of libraries sizes exceeding $\sim 10^{5}$ clones requires the use of single-cell assay formats [76]. Designing the appropriate selection or screening process for the isolation of clones with the desired phenotypes is a key factor for the implementation of genome engineering strategies for enhanced recombinant protein production. A number of highthroughput selection/screening systems have been developed and/or utilized in the past few years for the development of such overexpressing strains.

2.3.1 Genetic selection The levels of accumulation of a protein of interest can be coupled with the growth of the host cell under selective conditions by expressing the target protein in the form of a chimeric fusion with a reporter protein which exhibits a selectable phenotype, such as an antibiotic resistance marker. Bowie and coworkers, for example, isolated E. coli strains with enhanced capacity for integral membrane protein expression by selecting for antibiotic resistance conferred by expressing two separate C-terminal fusions of the $M$. tuberculosis rhomboid membrane protein Rv1337 to chroramphenicol acetyltransferase (the enzyme conferring resistance to the antibiotic chloramphenicol) or aminoglycoside 3'-phosphotransferase (the enzyme conferring resistance to the antibiotic kanamycin) [60]. Our group has developed a simple genetic selection system for enhanced recombinant membrane protein production in $E$. coli, by utilizing a tripartite fusion comprising the human GPCR BR2 with an Nterminal DsbA leader sequence, which targets the recombinant protein to the signal recognition particle pathway for insertion into the bacterial inner membrane, and a C-terminal $\beta$-lactamase [64]. A number of similar approaches have been developed using chloramphenicol acetyltransferase $[77,78]$ and dihydrofolate reductase (DHFR) [79], or combinations of these [80] as fusion reporter proteins.

Recently, protein fragment complementation assays were developed especially for monitoring protein folding and expression. In this systems, the protein of interest is inserted into the middle of a reporter gene, such as $\beta$-gatactosidase [81], $\beta$-lactamase [82], or GFP [83-85]. Since the activity of the reporter is designed to be recovered only when the correct folding of the test protein has occurred, its activity is proportional to the level of accumulation of correctly folded protein in the cell.

Recently, DeLisa and colleagues developed a novel selection platform for protein folding, by capitalizing on the properties of the bacterial twin-arginine translocation 
(Tat) pathway [86]. The bacterial Tat pathway is a Secindependent inner membrane transport system that is known for its ability to transport only proteins that have undergone folding before translocation [87]. In this system, a protein of interest is inserted between an N-terminal Tat signal peptide and a $C$-terminal $\beta$-lactamase enzyme. Since $\beta$-lactamase is active when it is exported into the periplasm, only cells with correctly folded target protein can survive on antibiotic-containing selective media.

2.3.2. High-throughput screening using fluorescent reporters Since the original observation by Waldo and co-workers that the fluorescence of E. coli cells expressing a C-terminal fusion of a recombinant protein with the green fluorescent protein (GFP) correlates well with the expression levels of well folded and soluble protein [88], fluorescent proteins have been widely used to monitor the expression level for both soluble and membrane-embedded proteins $[7,62,89,90]$. Microplates using a fluorescence plate reader, dot blot analyses using a fluorescence scanner, or flow cytometry are routinely used for monitoring the fluorescence of GFP fusions [91-93]. Flow cytometry is by far the most powerful tool for fluorescence-based library screening in terms of throughput, ability to monitor fluorescence at the single-cell level in a quantitative manner, and the isolation of desired clones [7,62,76,89].

The accumulation of active, secreted protein at the single-cell level can be readily monitored by periplasmic expression followed by cytometric sorting (PECS) [94]. In this technique, E. coli cells expressing a protein in the periplasm are incubated in a high-osmolarity buffer that renders their outer membrane permeable to a ligand labeled with a fluorescent probe (Figure 1) [94]. The fluorescent ligand binds to the properly folded protein, conferring cell fluorescence proportional to the amount of functional protein in the periplasm. Clones containing mutations that increase the expression of functional protein, display higher fluorescence and can be isolated by FACS. By using this technique, we have isolated several E. coli mutant strains which accumulate markedly enhanced quantities of full-length and properly assembled

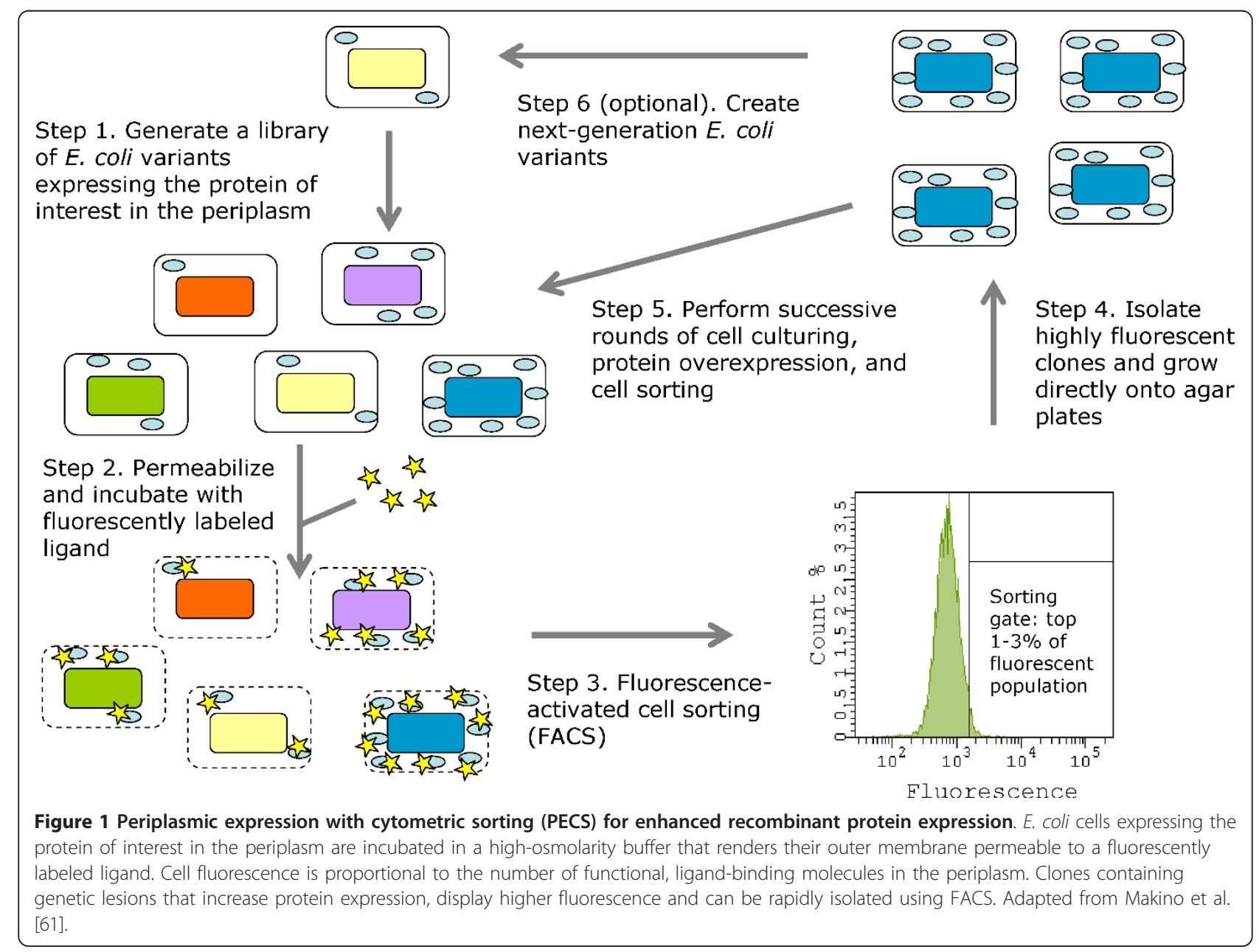


IgG antibodies in the bacterial periplasm [61]. Furthermore, we have utilized PECS to isolate several genes and gene clusters which confer high expression levels of properly folded integral membrane proteins, including several mammalian GPCRs and native bacterial membrane proteins [GS, TM, Navin Varadarajan, Mark Pogson, and GG; manuscript in preparation].

\section{Conclusion}

Recent studies have demonstrated that strain/genetic engineering is a very promising approach for evolving engineered $E$. coli strains with markedly enhanced capacities for recombinant protein production. Several unique and powerful methods have emerged recently that allow the generation of large libraries of bacterial mutants carrying different types of genetic profiles. Furthermore, advances in high-throughput screening have enabled the monitoring of the overexpression phenotype at the single-cell level and the rapid isolation of the rare clones with the desired overexpression profiles. The information obtained from the analysis of the genetic profiles in the isolated strains can provide invaluable and fundamental understanding about the biology of protein biogenesis, folding, stability and homeostasis in bacteria. These pieces of information can subsequently be combined and utilized to generate specialized protein expression bacterial "cell factories" for uses in research as well as in the industrial field.

\section{Acknowledgements}

The authors would like to thank Xin Ge and Eric Quandt for useful comments on the manuscript. This work was supported by grants from the Clayton Foundation and by the Advanced Technology Program of the State of Texas.

\section{Author details}

'Department of Chemical Engineering, The University of Texas at Austin, Austin, Texas 78712, USA. ${ }^{2}$ Institute for Cellular and Molecular Biology, The University of Texas at Austin, Austin, Texas 78712, USA. ${ }^{3}$ Department of Biomedical Engineering, The University of Texas at Austin, Austin, Texas 78712, USA. ${ }^{4}$ Section of Molecular Genetics and Microbiology, The University of Texas at Austin, Austin, Texas 78712, USA. ${ }^{5}$ Insitute of Biological Research and Biotechnology, National Hellenic Research Foundation, 48 Vassileos Constantinou Ave., 11635 Athens, Greece. ${ }^{6}$ Asubio Pharma CO., LTD. 6-4-3, Minatojima-Minamimachi Chuo-ku, Kobe 650-0047, Japan.

\section{Authors' contributions}

All authors defined the topic of the review and wrote, read and approved the manuscript.

\section{Competing interests}

The authors declare that they have no competing interests.

Received: 28 January 2011 Accepted: 14 May 2011

Published: 14 May 2011

\section{References}

1. Burgess-Brown NA, Sharma S, Sobott F, Loenarz C, Oppermann U, Gileadi O: Codon optimization can improve expression of human genes in Escherichia coli: A multi-gene study. Protein Expr Purif 2008, 59(1):94-102.
2. Jung ST, Kang TH, Georgiou G: Efficient expression and purification of human aglycosylated Fcgamma receptors in Escherichia coli. Biotechnol Bioeng 2010, 107(1):21-30.

3. Simmons LC, Yansura DG: Translational level is a critical factor for the secretion of heterologous proteins in Escherichia coli. Nat Biotechnol 1996, 14(5):629-634.

4. Wu X, Jornvall H, Berndt KD, Oppermann U: Codon optimization reveals critical factors for high level expression of two rare codon genes in Escherichia coli: RNA stability and secondary structure but not tRNA abundance. Biochem Biophys Res Commun 2004, 313(1):89-96.

5. Pfleger BF, Pitera DJ, Smolke CD, Keasling JD: Combinatorial engineering of intergenic regions in operons tunes expression of multiple genes. Nat Biotechnol 2006, 24(8):1027-1032.

6. Hatfield GW, Roth DA: Optimizing scaleup yield for protein production: Computationally Optimized DNA Assembly (CODA) and Translation Engineering. Biotechnol Annu Rev 2007, 13:27-42

7. Kudla G, Murray AW, Tollervey D, Plotkin JB: Coding-sequence determinants of gene expression in Escherichia coli. Science 2009, 324(5924):255-258

8. Cho HJ, Lee Y, Chang RS, Hahm MS, Kim MK, Kim YB, Oh YK: Maltose binding protein facilitates high-level expression and functional purification of the chemokines RANTES and SDF-1alpha from Escherichia coli. Protein Expr Purif 2008, 60(1):37-45.

9. Kapust RB, Waugh DS: Escherichia coli maltose-binding protein is uncommonly effective at promoting the solubility of polypeptides to which it is fused. Protein Sci 1999, 8(8):1668-1674.

10. Rabhi-Essafi I, Sadok A, Khalaf N, Fathallah DM: A strategy for high-level expression of soluble and functional human interferon alpha as a GSTfusion protein in E. coli. Protein Eng Des Sel 2007, 20(5):201-209.

11. de Marco A: Protocol for preparing proteins with improved solubility by co-expressing with molecular chaperones in Escherichia coli. Nat Protoc 2007, 2(10):2632-2639.

12. Graves PE, Henderson DP, Horstman MJ, Solomon BJ, Olson JS: Enhancing stability and expression of recombinant human hemoglobin in E. coli: Progress in the development of a recombinant $\mathrm{HBOC}$ source. Biochim Biophys Acta 2008, 1784(10):1471-1479.

13. Sarkar CA, Dodevski I, Kenig M, Dudli S, Mohr A, Hermans E, Pluckthun A: Directed evolution of a G protein-coupled receptor for expression, stability, and binding selectivity. Proc Natl Acad Sci USA 2008, 105(39):14808-14813.

14. Fisher AC, DeLisa MP: Efficient isolation of soluble intracellular singlechain antibodies using the twin-arginine translocation machinery. $J \mathrm{Mol}$ Biol 2009, 385(1):299-311.

15. Seo MJ, Jeong KJ, Leysath $C E$, Ellington $A D$, Iverson $B L$, Georgiou $G$ : Engineering antibody fragments to fold in the absence of disulfide bonds. Protein Sci 2009, 18(2):259-267.

16. Baneyx F, Mujacic M: Recombinant protein folding and misfolding in Escherichia coli. Nat Biotechnol 2004, 22(11):1399-1408.

17. Choi JH, Lee SY: Secretory and extracellular production of recombinant proteins using Escherichia coli. Appl Microbiol Biotechnol 2004, 64(5):625-635.

18. Georgiou G, Segatori L: Preparative expression of secreted proteins in bacteria: status report and future prospects. Curr Opin Biotechnol 2005 16(5):538-545.

19. Gottesman S: Proteases and their targets in Escherichia coli. Annu Rev Genet 1996, 30:465-506.

20. Lopez PJ, Marchand I, Joyce SA, Dreyfus M: The C-terminal half of RNase $E$, which organizes the Escherichia coli degradosome, participates in mRNA degradation but not rRNA processing in vivo. Mol Microbiol 1999, 33(1):188-199.

21. Baca AM, Hol WG: Overcoming codon bias: a method for high-level overexpression of Plasmodium and other AT-rich parasite genes in Escherichia coli. Int J Parasitol 2000, 30(2):113-118.

22. Sorensen HP, Sperling-Petersen HU, Mortensen KK: Production of recombinant thermostable proteins expressed in Escherichia coli: completion of protein synthesis is the bottleneck. J Chromatogr B Analyt Technol Biomed Life Sci 2003, 786(1-2):207-214.

23. Houry WA: Chaperone-assisted protein folding in the cell cytoplasm. Curr Protein Pept Sci 2001, 2(3):227-244.

24. Bothmann $\mathrm{H}$, Pluckthun A: The periplasmic Escherichia coli peptidylprolyl cis, trans-isomerase FkpA. I. Increased functional expression of antibody 
fragments with and without cis-prolines. J Biol Chem 2000, 275(22):17100-17105.

25. Hu X, O'Hara L, White S, Magner E, Kane M, Wall JG: Optimisation of production of a domoic acid-binding scFv antibody fragment in Escherichia coli using molecular chaperones and functional immobilisation on a mesoporous silicate support. Protein Expr Purif 2007, 52(1):194-201

26. Link AJ, Skretas G, Strauch EM, Chari NS, Georgiou G: Efficient production of membrane-integrated and detergent-soluble $\mathrm{G}$ protein-coupled receptors in Escherichia coli. Protein Sci 2008, 17(10):1857-1863.

27. Nishihara K, Kanemori M, Yanagi H, Yura T: Overexpression of trigger factor prevents aggregation of recombinant proteins in Escherichia coli. Appl Environ Microbiol 2000, 66(3):884-889

28. Skretas G, Carroll S, DeFrees S, Schwartz MF, Johnson KF, Georgiou G. Expression of active human sialyltransferase ST6GaINAcl in Escherichia coli. Microb Cell Fact 2009, 8:50

29. Genevaux P, Keppel F, Schwager F, Langendijk-Genevaux PS, Hartl FU, Georgopoulos C: In vivo analysis of the overlapping functions of DnaK and trigger factor. EMBO Rep 2004, 5(2):195-200.

30. Saul FA, Arie JP, Vulliez-le Normand B, Kahn R, Betton JM, Bentley GA Structural and functional studies of FkpA from Escherichia coli, a cis/ trans peptidyl-prolyl isomerase with chaperone activity. J Mol Biol 2004, 335(2):595-608

31. de Marco A, Deuerling E, Mogk A, Tomoyasu T, Bukau B: Chaperone-based procedure to increase yields of soluble recombinant proteins produced in E. coli. BMC Biotechnol 2007, 7:32.

32. Kadokura H, Katzen F, Beckwith J: Protein disulfide bond formation in prokaryotes. Annu Rev Biochem 2003, 72:111-135.

33. de Marco A: Strategies for successful recombinant expression of disulfide bond-dependent proteins in Escherichia coli. Microb Cell Fact 2009, 8:26.

34. Kurokawa Y, Yanagi H, Yura T: Overproduction of bacterial protein disulfide isomerase (DsbC) and its modulator (DsbD) markedly enhances periplasmic production of human nerve growth factor in Escherichia coli. J Biol Chem 2001, 276(17):14393-14399.

35. Qiu J, Swartz JR, Georgiou G: Expression of active human tissue-type plasminogen activator in Escherichia coli. Appl Environ Microbiol 1998 64(12):4891-4896.

36. Bessette PH, Aslund F, Beckwith J, Georgiou G: Efficient folding of proteins with multiple disulfide bonds in the Escherichia coli cytoplasm. Proc Natl Acad Sci USA 1999, 96(24):13703-13708.

37. Faulkner MJ, Veeravalli K, Gon S, Georgiou G, Beckwith J: Functional plasticity of a peroxidase allows evolution of diverse disulfide-reducing pathways. Proc Natl Acad Sci USA 2008, 105(18):6735-6740.

38. Nguyen VDHF, Salo KE, Enlund E, Zhang C, Ruddock LW: Pre-expression of a sulfhydryl oxidase significantly increases the yields of eukaryotic disulfide bond containing proteins expressed in the cytoplasm of E.coli. Microb Cell Fact 2011, 10(1):1

39. Hatahet FNV, Salo KE, Ruddock LW: Disruption of reducing pathways is not essential for efficient disulfide bond formation in the cytoplasm of E. coli. Microb Cell Fact 2010, 13(9):67.

40. Wacker M, Linton D, Hitchen PG, Nita-Lazar M, Haslam SM, North SJ, Panico M, Morris HR, Dell A, Wren BW, et al: N-linked glycosylation in Campylobacter jejuni and its functional transfer into E. coli. Science 2002, 298(5599):1790-1793.

41. Linton D, Dorrell N, Hitchen PG, Amber S, Karlyshev AV, Morris HR, Dell A, Valvano MA, Aebi M, Wren BW: Functional analysis of the Campylobacter jejuni N-linked protein glycosylation pathway. Mol Microbiol 2005, 55(6):1695-1703.

42. Pandhal J, Wright PC: N-Linked glycoengineering for human therapeutic proteins in bacteria. Biotechnol Lett 2010, 32(9):1189-1198.

43. Pandhal JOS, Noirel J, Wright PC: Improving N-glycosylation efficiency in Escherichia coli using shotgun proteomics, metabolic network analysis, and selective reaction monitoring. Biotechnol Bioeng 2010

44. Feldman MF, Wacker M, Hernandez M, Hitchen $P G$, Marolda CL, Kowarik M, Morris HR, Dell A, Valvano MA, Aebi M: Engineering N-linked protein glycosylation with diverse $\mathrm{O}$ antigen lipopolysaccharide structures in Escherichia coli. Proc Natl Acad Sci USA 2005, 102(8):3016-3021.

45. Ihssen J, Kowarik M, Dilettoso S, Tanner C, Wacker M, Thony-Meyer L: Production of glycoprotein vaccines in Escherichia coli. Microb Cell Fact 2010, 9:61.
46. Celik E, Fisher AC, Guarino C, Mansell TJ, Delisa MP: A filamentous phage display system for N-linked glycoproteins. Protein Sci 2010.

47. Durr C, Nothaft H, Lizak C, Glockshuber R, Aebi M: The Escherichia coli glycophage display system. Glycobiology 2010, 20(11):1366-1372.

48. Kouzarides T: Acetylation: a regulatory modification to rival phosphorylation? EMBO J 2000, 19(6):1176-1179.

49. Arnesen T, Van Damme P, Polevoda B, Helsens K, Evjenth R, Colaert N, Varhaug JE, Vandekerckhove J, Lillehaug JR, Sherman F, et al: Proteomics analyses reveal the evolutionary conservation and divergence of $\mathrm{N}$ terminal acetyltransferases from yeast and humans. Proceedings of the National Academy of Sciences of the United States of America 2009, 106(20):8157-8162

50. Gautschi M, Just S, Mun A, Ross S, Rucknagel P, Dubaquie Y, EhrenhoferMurray A, Rospert $\mathrm{S}$ : The yeast $\mathrm{N}$ (alpha)-acetyltransferase NatA is quantitatively anchored to the ribosome and interacts with nascent polypeptides. Mol Cell Biol 2003, 23(20):7403-7414.

51. Soppa J: Protein acetylation in archaea, bacteria, and eukaryotes. Archaea 2010, 2010.

52. Fang $H$, Zhang $X$, Shen L, Si X, Ren Y, Dai H, Li S, Zhou C, Chen H: RimJ is responsible for $\mathrm{N}$ (alpha)-acetylation of thymosin alpha1 in Escherichia coli. Appl Microbiol Biotechnol 2009, 84(1):99-104.

53. Johnson M, Coulton AT, Geeves MA, Mulvihill DP: Targeted amino-terminal acetylation of recombinant proteins in E. coli. PLoS One 2010, 5(12): e15801.

54. Baba T, Ara T, Hasegawa M, Takai Y, Okumura Y, Baba M, Datsenko KA, Tomita M, Wanner BL, Mori H: Construction of Escherichia coli K-12 inframe, single-gene knockout mutants: the Keio collection. Mol Syst Biol 2006, 2, 20060008.

55. Alper $\mathrm{H}$, Stephanopoulos G: Global transcription machinery engineering: a new approach for improving cellular phenotype. Metab Eng 2007, 9(3):258-267.

56. Warner JR, Reeder PJ, Karimpour-Fard A, Woodruff LB, Gill RT: Rapid profiling of a microbial genome using mixtures of barcoded oligonucleotides. Nat Biotechnol 2010

57. Carr PA, Church GM: Genome engineering. Nat Biotechnol 2009, 27(12):1151-1162.

58. Miroux B, Walker JE: Over-production of proteins in Escherichia coli: mutant hosts that allow synthesis of some membrane proteins and globular proteins at high levels. J Mol Biol 1996, 260(3):289-298.

59. Wagner S, Klepsch MM, Schlegel S, Appel A, Draheim R, Tarry M, Hogbom M, van Wijk KJ, Slotboom DJ, Persson JO, et al: Tuning Escherichia coli for membrane protein overexpression. Proc Natl Acad Sci USA 2008, 105(38):14371-14376.

60. Massey-Gendel E, Zhao A, Boulting G, Kim HY, Balamotis MA, Seligman LM, Nakamoto RK, Bowie JU: Genetic selection system for improving recombinant membrane protein expression in E. coli. Protein Sci 2009, 18(2):372-383.

61. Makino T, Skretas G, Kang TH, Georgiou G: Comprehensive engineering of Escherichia coli for enhanced expression of IgG antibodies. Metab Eng 2011, 13(2):241-251.

62. Skretas G, Georgiou G: Genetic analysis of G protein-coupled receptor expression in Escherichia coli: inhibitory role of DnaJ on the membrane integration of the human central cannabinoid receptor. Biotechnol Bioeng 2009, 102(2):357-367.

63. Kitagawa M, Ara T, Arifuzzaman M, loka-Nakamichi T, Inamoto E, Toyonaga $\mathrm{H}$, Mori H: Complete set of ORF clones of Escherichia coli ASKA library (a complete set of E. coli K-12 ORF archive): unique resources for biological research. DNA Res 2005, 12(5):291-299.

64. Skretas G, Georgiou G: Simple genetic selection protocol for isolation of overexpressed genes that enhance accumulation of membraneintegrated human G protein-coupled receptors in Escherichia coli. Appl Environ Microbiol 2010, 76(17):5852-5859.

65. Santos CN, Stephanopoulos G: Combinatorial engineering of microbes for optimizing cellular phenotype. Curr Opin Chem Biol 2008, 12(2):168-176.

66. Klein-Marcuschamer D, Santos CN, Yu H, Stephanopoulos G: Mutagenesis of the bacterial RNA polymerase alpha subunit for improvement of complex phenotypes. Appl Environ Microbiol 2009, 75(9):2705-2711.

67. Alper H, Moxley J, Nevoigt E, Fink GR, Stephanopoulos G: Engineering yeast transcription machinery for improved ethanol tolerance and production. Science 2006, 314(5805):1565-1568. 
68. Yu H, Tyo K, Alper H, Klein-Marcuschamer D, Stephanopoulos G: A highthroughput screen for hyaluronic acid accumulation in recombinant Escherichia coli transformed by libraries of engineered sigma factors. Biotechnol Bioeng 2008, 101(4):788-796.

69. Park KS, Lee DK, Lee H, Lee Y, Jang YS, Kim YH, Yang HY, Lee SI, Seol W, Kim JS: Phenotypic alteration of eukaryotic cells using randomized libraries of artificial transcription factors. Nat Biotechnol 2003, 21(10):1208-1214.

70. Lee JY, Sung BH, Yu BJ, Lee JH, Lee SH, Kim MS, Koob MD, Kim SC: Phenotypic engineering by reprogramming gene transcription using novel artificial transcription factors in Escherichia coli. Nucleic Acids Res 2008, 36(16):e102.

71. Park KS, Jang YS, Lee H, Kim JS: Phenotypic alteration and target gene identification using combinatorial libraries of zinc finger proteins in prokaryotic cells. J Bacteriol 2005, 187(15):5496-5499.

72. Zhang YX, Perry K, Vinci VA, Powell K, Stemmer WP, del Cardayre SB: Genome shuffling leads to rapid phenotypic improvement in bacteria. Nature 2002, 415(6872):644-646.

73. Patnaik R, Louie S, Gavrilovic V, Perry K, Stemmer WP, Ryan CM, del Cardayre S: Genome shuffling of Lactobacillus for improved acid tolerance. Nat Biotechnol 2002, 20(7):707-712.

74. Dai M, Copley SD: Genome shuffling improves degradation of the anthropogenic pesticide pentachlorophenol by Sphingobium chlorophenolicum ATCC 39723. Appl Environ Microbiol 2004, 70(4):2391-2397.

75. Dai M, Ziesman S, Ratcliffe T, Gill RT, Copley SD: Visualization of protoplast fusion and quantitation of recombination in fused protoplasts of auxotrophic strains of Escherichia coli. Metab Eng 2005, 7(1):45-52.

76. Link AJ, Jeong KJ, Georgiou G: Beyond toothpicks: new methods for isolating mutant bacteria. Nat Rev Microbiol 2007, 5(9):680-688.

77. Maxwell $\mathrm{KL}$, et al: A simple in vivo assay for increased protein solubility. Protein Science 1999, 8(9):1908-1911.

78. Maxwell KL, Mittermaier AK, Forman-Kay JD, Davidson AR: A simple in vivo assay for increased protein solubility. Protein Science 1999, 8(9):1908-1911.

79. Liu JW, Boucher Y, Stokes HW, Ollis DL: Improving protein solubility: the use of the Escherichia coli dihydrofolate reductase gene as a fusion reporter. Protein Expr Purif 2006, 47(1):258-263.

80. Japrung D, Chusacultanachai S, Yuvaniyama J, Wilairat P, Yuthavong Y: A simple dual selection for functionally active mutants of Plasmodium falciparum dihydrofolate reductase with improved solubility. Protein Eng Des Sel 2005, 18(10):457-464.

81. Wigley WC, Stidham RD, Smith NM, Hunt JF, Thomas PJ: Protein solubility and folding monitored in vivo by structural complementation of a genetic marker protein. Nat Biotechnol 2001, 19(2):131-136.

82. Foit L, Morgan GJ, Kern MJ, Steimer LR, von Hacht AA, Titchmarsh J, Warriner SL, Radford SE, Bardwell JC: Optimizing protein stability in vivo. Mol Cell 2009, 36(5):861-871.

83. Cabantous S, Pedelacq JD, Mark BL, Naranjo C, Terwilliger TC, Waldo GS: Recent advances in GFP folding reporter and split-GFP solubility reporter technologies. Application to improving the folding and solubility of recalcitrant proteins from Mycobacterium tuberculosis. J Struct Funct Genomics 2005, 6(2-3):113-119.

84. Cabantous S, Terwilliger TC, Waldo GS: Protein tagging and detection with engineered self-assembling fragments of green fluorescent protein. Nat Biotechnol 2005, 23(1):102-107.

85. Cabantous $\mathrm{S}$, Waldo GS: In vivo and in vitro protein solubility assays using split GFP. Nat Methods 2006, 3(10):845-854.

86. Fisher AC, Kim W, DeLisa MP: Genetic selection for protein solubility enabled by the folding quality control feature of the twin-arginine translocation pathway. Protein Sci 2006, 15(3):449-458.

87. Lee PA, Tullman-Ercek D, Georgiou G: The bacterial twin-arginine translocation pathway. Annu Rev Microbiol 2006, 60:373-395.

88. Waldo GS, Standish BM, Berendzen J, Terwilliger TC: Rapid protein-folding assay using green fluorescent protein. Nature Biotechnology 1999, 17(7):691-695.

89. Drew D, Sjostrand D, Nilsson J, Urbig T, Chin CN, de Gier JW, von Heijne G: Rapid topology mapping of Escherichia coli inner-membrane proteins by prediction and PhoA/GFP fusion analysis. Proc Natl Acad Sci USA 2002, 99(5):2690-2695.

90. Kim KH, Yang JK, Waldo GS, Terwilliger TC, Suh SW: From no expression to high-level soluble expression in Escherichia coli by screening a library of the target proteins with randomized N-termini. Methods Mol Biol 2008 426:187-195.

91. Coleman MA, Lao VH, Segelke BW, Beernink PT: High-throughput, fluorescence-based screening for soluble protein expression. J Proteome Res 2004, 3(5):1024-1032.

92. Omoya K, Kato Z, Matsukuma E, Li A, Hashimoto K, Yamamoto Y, Ohnishi H, Kondo N: Systematic optimization of active protein expression using GFP as a folding reporter. Protein Expr Purif 2004, 36(2):327-332.

93. Cabantous S, Rogers Y, Terwilliger TC, Waldo GS: New molecular reporters for rapid protein folding assays. PLoS One 2008, 3(6):e2387.

94. Chen G, Hayhurst A, Thomas JG, Harvey BR, Iverson BL, Georgiou G: Isolation of high-affinity ligand-binding proteins by periplasmic expression with cytometric screening (PECS). Nat Biotechnol 2001, 19(6):537-542.

95. Klein-Marcuschamer D, Stephanopoulos G: Assessing the potential of mutational strategies to elicit new phenotypes in industrial strains. Proceedings of the National Academy of Sciences of the United States of America 2008, 105(7):2319-2324.

doi:10.1186/1475-2859-10-32

Cite this article as: Makino et al:: Strain engineering for improved expression of recombinant proteins in bacteria. Microbial Cell Factories 2011 10:32

\section{Submit your next manuscript to BioMed Central and take full advantage of:}

- Convenient online submission

- Thorough peer review

- No space constraints or color figure charges

- Immediate publication on acceptance

- Inclusion in PubMed, CAS, Scopus and Google Scholar

- Research which is freely available for redistribution

Submit your manuscript at www.biomedcentral.com/submit
Ciomed Central 